\title{
More present than absent: men who use domestic violence and their fathering
}

\section{Running Head: More present than absent dv and fathering}

Cathy Humphreys, Professor of Social Work, University of Melbourne

Kristin Diemer, Senior Research Fellow, University of Melbourne

Anna Bornemisza, Researcher, University of Melbourne

Anneliese Spiteri-Staines, Researcher, University of Melbourne

Rae Kaspiew, Senior Research Fellow, Australian Institute of Family Studies

Briony Horsfall, Senior Research Fellow, Australian Institute of Family Studies

Author for Correspondence:

Cathy Humphreys,

Department of Social Work,

University of Melbourne

Parkville, Victoria. 3010

Email: cathy.humphreys@unimelb.edu.au

Phone: 61-3-8347429

The authors wish to acknowledge the women and men who participated in the study and the support of the advisory groups who provided support for the project. The research was funded by the Australian National Research Organisation for Women's Safety. The views expressed in the article are those of the authors and do not necessarily reflect those of the funding body.

This is the author manuscript accepted for publication and has undergone full peer review but has not been through the copyediting, typesetting, pagination and proofreading process, which may lead to differences between this version and the Version of Record. Please cite this article as doi: $10.1111 / \mathrm{cfs} .12617$

This article is protected by copyright. All rights reserved. 


\begin{abstract}
An earlier article referred to the 'absent presence' of the perpetrator in the lives of children and their mothers who have lived with domestic violence. It identified the ways in which the shadow of the perpetrator continued and was evidenced in the 'symptoms of abuse' that both women and children experienced in spite of his absence. The current article argues that fathers who use violence are actually more present than absent in the lives of children (and women) even following separation. A mixed method approach surveyed men in Men's Behaviour Change Programs ( $\mathrm{N}=101)$ and interviewed women who had experienced violence $(\mathrm{N}=50)$. The studies reported that the majority of men in both the quantitative men's study (80\%) and the qualitative women's study (77\%) had substantial contact with children. The women's interviews highlight the problematic fathering that many of their children experienced both before and after separation. They reported very high levels of child abuse and poor attitudes to both women and children.

The article concludes that the family violence and child welfare systems are poorly configured to address fathers who use violence who continue to hold substantial parenting roles including following separation.
\end{abstract}

Key words: domestic violence; fathers; child abuse; post-separation violence

\title{
More Present Than Absent: men who use domestic violence and their fathering
}

An earlier article referred to the' absent presence' of perpetrators of violence in the lives of children who had experienced domestic violence (Anonymised). It highlighted the multiple ways that the shadow of the perpetrator of violence continued to be cast over the lives of children and their mothers even following separation. Generally, this referred to the ways in which traumatic memories and experiences of the abuse manifested in children's physical and emotional well-being. Children who were unable to sleep, who had nightmares, who had angry outbursts and low self-esteem were some of the many symptoms of abuse which were reported (Anonymised).

This article continues this theme. However, based on different research it points to the ways in which fathers who use violence may remain more present than absent in the lives of their children. The article begins with an overview of relevant literature and the methodology for the research, prior to outlining the key findings. The discussion explores the complex issues raised in recognising that the majority of fathers who use violence remain present in children's lives.

\section{Relevant literature}

This article is protected by copyright. All rights reserved. 
An interesting lacunae has developed in understanding the relationship between domestic violence and child abuse. The evidence is consistent across all studies that exposure to domestic violence is harmful to children (McTavish et al, 2016; Kimball, 2016). These studies indicate that, although not all children are similarly affected, that there are high risks to the behavioural, cognitive and emotional development of children (Holt, Buckley \& Whelan, 2008). Studies also highlight the gendered nature of domestic violence and that violence is primarily perpetrated by men against women particularly when referring to intimate partner violence between heterosexual couples (Walby \& Allen, 2004). Together these data identify that domestic violence is a form of child abuse and that the dominant pattern shows that this child abuse is perpetrated by the child's father (biological or social). .While domestic violence is frequently referred to as a form of violence against women, the identification of 'fathers who use violence' is not common terminology (Anonymised). The language used can hide the fathers' destructive impact on his children creating harm through both his direct and indirect behaviours (Mandel, 2014).

Children witnessing, living with, or exposed to domestic violence is the terminology often used to recognise that children may not be the primary target, but they are nevertheless significantly impacted by intimate partner violence (Levendosky, Bogat, Martinez-Torteya, 2013). The indirect nature of the harm may obfuscate the responsibility of fathers for harming their children through undermining the child's mother (physically and emotionally), through comprising the functioning of the family, and creating an atmosphere of fear in which children are unable to thrive (Lourenco et al, 2013).

The association of domestic violence with the direct abuse of children has also been explored (Herrenkhol et al, 2008). Studies suggest between $30 \%$ and $66 \%$ of children who suffer physical abuse are also living with domestic abuse. The wide variation is largely dependent upon research site and methodology (Kimball, 2016). The severity of violence is also relevant, with the US study by Ross (1996), finding almost a 100\% correlation between the most severe abuse of women and the men's physical abuse of children. Other studies confirm this trend (Hartley, 2004; Kimball, 2016).

The number of Adverse Childhood Experiences (ACEs) that children living with domestic violence may experience and the impact that this can have on their health and mental health is highly relevant to this discussion (Oral et al, 2016). Studies suggest that living with domestic violence is the strongest predictor of other adverse experiences and therefore a significant indicator of distress across the lifespan (McGavock \& Spratt, 2017).

There has been less attention paid to the parenting practices of men who use violence against their partners. It is an emerging area of research raising significant cause for concern 
(Stover \& Margos, 2013). Qualitative research studies identify a group of men who have poor parenting skills resulting from their sense of entitlement, self-centred attitudes and over-controlling behaviour (Scott \& Crooks, 2007), and who over- use physical forms of discipline (smacking) when compared with other fathers (Fox \& Benson, 2004). They may have a poor understanding of child development and the tactics of abuse used against partners often extend to children (Katz, 2016; Heward-belle, 2016). These tactics include undermining of the child's mother and her parenting (Thompson-Walsh et al, 2018).

Safety for both women and children has been conflated with separation, in spite of the fact that separation and the process of separation are associated with heightened risks of homicide and on-going abuse (Rezey, 2017). The 2016 police data in Victoria indicates that 40 percent of incidents of domestic violence were post-separation, thus providing little respite for many families. Moreover, children in separated families frequently have on-going time with their fathers, in spite of the history of domestic violence. It is an area where the 'pro-contact' family law (private law) system is often at odds with statutory child protection, where the latter may insist on separation as a route to safety for children (Hester, 2011).

While Men's Behaviour Change (MBC or perpetrator) programs have been developed to respond to men who use violence (Kelly \& Westmarland, 2015), there has been less attention to the fathering practices of these men. Customised group work programs are in the early stages of development and evaluation (Scott and Crooks, 2007; McConnell et al, 2016) and there has been little attention to the response to families where separation has not occurred (Anonymised).

The confusion surrounding the role of fathers who use violence in the policy and practice context contributed to the identification of research questions which informed this article:

How, and under what circumstances are fathers who use violence parenting?

What do mothers report about the parenting of fathers who have been domestically violent?

\section{Methodology}

A mixed method design was used to draw different perspectives on the parenting practices of men who use violence (Creswell \& Plano Clark, 2007). It was recognised that the views of women who have mothered through violence would provide an important but very specific perspective on the parenting practices of their partners and ex-partners. They provide one lens on 'how and under what circumstances men who use violence are parenting'. A different lens is provided by survey data of men who attend men's behaviour change programs about how and under what circumstances they are parenting. For the purposes of 
this study, quantitative and qualitative methods combine to provide an expanded understanding of the subject (Johnson, Onwuegbuzie, \& Turner, 2007).

The survey used in MBC programs was situated in a larger program of research, Fathering Challenges: Responsive, Responsible Reparative fathering in the context of domestic violence. The men's survey involved 101 useable questionnaires from men from two states in Australia involving rural and urban settings. Questionnaires took on average 30-40 minutes to complete. Participants were recruited at the $\mathrm{MBC}$ programs they attended and almost all men in attendance filled out a questionnaire sometimes with support from the researcher when required. The questionnaire focused on answering the first research question. Data collection took place between May and August 2016. Ethics clearance was provided through University of Melbourne.

The women's interviews had a more complex process of recruitment and consent. An aspect of the Fathering Challenges research program required interviews with women to provide a perspective on both mothering and fathering through violence. The chief investigator on this program was also engaged in another program of research which involved interviews with women and explored further aspects of mothering in the context of domestic violence, Domestic violence and parenting, mixed methods insights into impact and support needs (Anonymised). It was agreed between the project teams that ethical clearance and consent from women would be sought for their contribution to both projects with the use of the same interview schedule. The plain language statement outlined both projects and women consented for their interview data to be used in one or both projects. All women agreed to have their interview data used for both projects. Ethical clearance was provided by both the Australian Institute of Family Studies and University of Melbourne.

Fifty women were recruited from across Australia drawn from sites that were accessed through the stakeholder services involved in both projects. Refuges, family relationship centres, partner programs associated with MBC programs, and specialist women's domestic violence services supported access to women. Interviews were taped, transcribed and analysed by the researchers. It was agreed to use a thematic analysis (Thomas and Harden, 2008) with the initial primary coding led by one researcher. The thematic coding framework was then agreed through a 'data party' with researchers from both teams coming together to analyse transcripts, test inter-relater reliability and for each research team to take responsibility for the analysis of particular themes across all 50 transcripts (for example one team had a focus on fathering, another on experiences of service provision).

\section{Findings}

Men's Behaviour Change Questionnaire 
The family lives of the men on MBC programs are complicated and often involved children with different mothers. Only men with children responded to the survey. Between these 101 men there were 268 children, an average of 2.6 for each man. For this research project, men were asked to think about a child they found most difficult to manage and report details of their contact with that child. The results are based on the relationship with that one child. Nearly two-fifths of the men $(N=38)$ reported they lived with this child full time and a further third $(\mathrm{N}=34)$ who did not live with their child, saw their child once a week or more. No contact was rare. Table 1 presents the counts of frequency of contact fathers have with their child.

Insert Table 1

Of the contact arrangements, most had been negotiated informally and only $21 \%(\mathrm{~N}=18)$ were court ordered. Almost half the men were living with their partner (47\%), and almost one-third (28\%) had separated from their partner (Table 2).

Insert Table 2

While not significant, the data suggests that men had more difficulty with their biological sons, though daughters still comprised $38 \%$ of the sample. A further issue raised in the data, was that although biological children were the majority of children men noted as 'most difficult' (77\%), there were also difficulties with step-children, and nieces/nephews (26\%). Table 3 indicates the gender and relationship with the children the men identified as 'most difficult'.

Insert Table 3

\section{Qualitative interviews with women}

Of the 50 women interviewed, 46 had separated from their abusive partner, and of the four participants still living with the perpetrator, one was separated though still sharing a house. The women had 142 children between them. While a scale was not used to systematically record the abuse they had experienced, most women reported abuse at the severe end of a continuum of violence, with reports of hospitalisation with injuries, incidents of serious physical and sexual violence, stalking and highly controlling tactics of abuse.

\section{Under what circumstances were men parenting}

The living arrangements for children were fluid and complicated. A total of 70 percent $(n=$ 35) of mothers who were separated from their ex-partner had at least one child mainly living with them. However, within this group of mothers, six reported that at least one of their other children lived mainly with their father (that is siblings had different postseparation arrangements). Six mothers reported all children mainly lived with their father

This article is protected by copyright. All rights reserved. 
and another six mothers reported having an equal, time shared care arrangement. Nine mothers reported that children had weekly or more overnight stays with their father in circumstances where the child mainly lived with her.

The care arrangements culminated with $77 \%(\mathrm{~N}=27)$ mothers reporting one or more children living mainly with the father who used violence on a shared care, full-time basis, or having substantial overnight care-time. Twenty-four percent $(\mathrm{N}=12)$ mothers had a child mainly living with them where there were no overnight stays with the father (meaning only daytime or no contact occurred with him).

Decisions were eventually made which affected six fathers (with extensive contact mentioned above) who were moved to supervised contact or no contact following reports of serious child abuse associated with child contact arrangements.

\section{Forms of child abuse}

Interview transcripts were analysed for specific references to child abuse allegedly perpetuated by fathers. Women were asked generally about fathering rather than specifically about forms of child abuse, hence there may be abuse and neglect which women did not mention in their interviews.

The frequencies and forms of child abuse are described to provide a picture of the patterns of abuse. Table 4 presents these frequencies. The numbers in the coding refer to participants, rather than per child. A total of 45 out of 50 mothers $(90 \%)$ referred to one or more types of child abuse and the total indicates that two or more types were present in most cases.

Insert Table 4 here

\section{Direct physical abuse of children}

The direct physical abuse of children by their fathers was reported by 17 women.

She had marks from the middle of her back right down to underneath her bottom, and like, you could clearly see the red handprint, like, the individual fingers. (Patricia)

Not all women referred to physical child abuse but often used terms such as, "he was physical to her" or "he was overly hard".

He was very harsh on them and very controlling and...inappropriate use of discipline. Throwing, you know, [child] on his bed so [child's] head hit the wall and that sort of thing...Banishing them. Dinner times were terrible 'cause, they' $d$ always end up in this family violence incident and, he'd banish the children outside like animals in winter. (Nicole)

In this sample, five women experienced the "double intentioned" (Kelly, 1994) violence of being assaulted during pregnancy (an attack on both the mother and the unborn child). 
He [ex-partner] kicked me when I was pregnant with her and I was stressed out a lot. She's lucky to be alive. I ended up in hospital when he hurt me. It was the police that took me to hospital. Me and my four kids. (Audrey)

Some mothers reported that physical child abuse occurred when children were having postseparation contact with their father.

Handing over to the father was really traumatic. You know coming home was even more traumatic...there were bruises everywhere. Everywhere. Like all down her back. Her legs. Her front. Her neck. Her face. It's just-it was just too much...when I asked her what happened she said, "I don't know." So you know, she was terrified. (Bianca)

Several women identified the physical or sexual abuse of children as the point where they decided that they must separate:

When the violence started going towards [son], that's when I knew I had to go.

(Cheryl)

\section{Sexual abuse of children}

Five mothers spoke about their children having been sexually abused. However, criminal charges were uncommon and potentially problematic. For example, Mackenzie's daughter pursued criminal charges when she reached adulthood. Allegations of sexual abuse could also escalate post-separation proceedings in a way that meant fathers could make counterallegations through alleging alienation or making false allegations against mothers.

Bianca's children had contact with their father in compliance with a shared parenting caretime court order. However, the father and his new partner physically abused the children and the father's new partner engaged in sexually abusive behaviour:

Obviously, at this time, I didn't know...bruises started showing. There were some other things as well. Some other forms of abuse that I didn't know were abuse at the time. And she'd had vaginal irritation and was coming home with marks on her...we knew the kids were deteriorating and, but they weren't talking. But something was very, very wrong. (Bianca)

\section{Emotional, psychological and verbal child abuse}

While it could be argued that all children living with domestic violence are exposed to emotional or psychological abuse, 31 mothers in this sample reported psychological/emotional abuse of the children.

So that was hard, and he was very cruel to the animals and that was extremely hard on the kid... he really liked pornography on the internet, and every now and then he would leave it up and the [children] would go to the internet and all these pornographic pictures would come up and things like that. (Rita)

At times, verbal abuse could escalate to incidents of bullying and humiliation: 
So for example, with [eldest child] -well my parents have a shack and so he would put [eldest child] behind the boat and make him do like knee boarding even though he was screaming and crying and saying he didn't want to do it. (Maryanne)

The majority of women spoke of incidents where children were impacted by exposure to the intimate partner violence.

And like, you know, last time I couldn't walk because I had been beaten up and I had to try and get up, get the clothes from outside of the washing machine into the basket and I was pushing the basket across the floor while pushing myself also across the floor. And my two little ones helped me. (Audrey)

Some children continued to witness family violence post-separation through handovers associated with parenting arrangements or breaches of intervention orders by fathers.

So that was the main thing, he was still entering my home and following me around abusing me for hours type stuff and in front of [child]. (Haley)

Threats and fear also took many forms. Vicky described how if she answered her telephone in the car her partner would swerve the car dangerously near to walls at the side of the road intimating that he could kill Vicky and the children, who were in the back seat.

In summary, the incidents of child abuse were entangled with the abuse of the child's mother. While children were sometimes the separate targets of abuse, at other times the abuse of mothers and their children were profoundly interconnected. Physical, sexual, psychological abuse of children occurred within a context of fear and control which also involved their mothers.

\section{Women's perspectives on men as fathers}

Women were asked to talk about the qualities of parenting that they observed and experienced with the child's father.

\section{Knowledge and skills as a father}

The majority of women in the sample reported that the fathers had little knowledge or skill about how to parent prior to separation. Mothers reported that fathers had never performed daily care tasks for their children such as bathing, preparing meals, getting them to school and assisting with homework, or engaging in age-appropriate play.

Women spoke of the lack of knowledge fathers had about child development that created unrealistic demands on children:

I was realistic about little kids and the mess they make. He demanded everything was tidy. There's no point in yelling at a 1 year old because they've got the coffee out all over the floor. Like, you've left them unsupervised in that time for them to get the coffee all over the floor. (Eloise) 
Sixteen women report mixed views of the father's parenting. They saw the fathers as offering positive fathering experiences for children but also talked about the undermining effects of DV. The experience of Lavinia is typical of this group.

Yeah, he was really good with the kids. He was very interactive. He was really good with them.... when he had energy. If he didn't have energy, he would completely shut down. And if he'd had enough, then you know, he might have an outburst of some kind...you know, he would do lots of stuff with my eldest child and he was very loving and affectionate with the youngest as well. (Lavinia)

But Lavinia also reflected that the children witnessed abuse towards her, and it was difficult to reconcile his positive actions as a father with the trauma he had caused the children.

But he didn't think verbally abusing me in front of them was a big deal or exploding if one of the children hurt themselves and kicking doors and screaming and hurling verbal abuse at the top of his lungs, didn't seem to count as verbal or abuse of any kind to him...I think that [the older child] definitely was involved in a couple of incidents that were extremely violent physically towards me. (Lavinia)

Lara spoke of extremely serious incidents of domestic violence and her ex-husband using ice.

He was very kind and loving and caring towards my girls and my other daughter. And he-he was just - I think - I guess the reason why I stayed with him was because he was so good to them, but-and I didn't see the bigger picture about him hurting me and the girls seeing that. (Lara)

\section{Attitudes to women and children}

Not all women articulated in the interviews that their (ex) partners had problematic attitudes to women. However, many were concerned about the ways in which attitudes to women might be, or were being, conveyed to their children.

He's the kind of person that perceives women to just be there to pretty much serve him and be servants and to not exist, to not have any other need or role whatsoever...So they have a really skewed view of what it means to be a woman. (Yvette)

Men's attitudes to children could be equally as problematic as their attitudes to women, with a number of women describing "seen and not heard" attitudes to children. Five women used the same phrase of "walking on eggshells" as a way to describe how children feared fathers and step-fathers.

My kids just started walking around on eggshells constantly. My kids weren't able to be kids really. They just-it was just always looking over my shoulder or trying to make them be quiet...it was just constant pressure trying to make them be silent and like silent little statues really. Ah yeah it was tough. (Kimberly) 


\section{Children replicating the behaviour of their fathers}

Mothers reported a number of disturbing behaviours occurring in their children as well as reporting children actively working to be different from their fathers.

[Son is] very gentle. In fact, I think he came into a really hard time of it, because he wouldn't be the kind of macho man that my partner expected him to be. So he's...I think his gentleness almost was validated, because he doesn't want to be that kind of person. (Rita)

However, there was also another strong theme in which women experienced their children repeating the abusive behaviour of their fathers. This was not a question on the interview schedule, but rather women, unprompted talked about this issue. Twenty mothers made direct reference to, and provided examples of, this distressing pattern of behaviour.

My [11 year old child] is starting to abuse me like her father. Same tone of voice, same voice, same actions...My youngest child [6 year old] I used to call my little sunshine. I used to sing that song, You are my sunshine all the time. Now she cries all the time. You know, they won't do as they're told, they trash the house, they break things, attention seeking behaviour. (Patricia)

It was particularly the case for some following contact visits; children (often, though not only boys) were seen to emulate their fathers' attitudes and behaviours:

They're lovely but also very difficult. They're coming back from his house very angry. My [child] ...last night, he had, like, a two-hour tantrum where he was throwing things and hitting his sister. And smashing windows, smashing doors. (Malene)

Some of the behaviour involved other children, either their siblings or their peers.

And this morning, he's trying to cut his sister with a knife and not understanding that that's not okay. Punching his friends... reacting violently. (Monica)

These challenging behaviours provided the backdrop for the relationship between a significant group of women and their children.

Men's mental health issues and drug, alcohol and gambling issues

Many women spoke during the interview in a way that sought to make sense of their partner or ex-partner's behaviour. Twelve women made reference to their partner or expartner's mental health problems, although it was difficult to glean how many of these men had received a clinical diagnosis. Several women referred to mood swings in this context.

[I wanted to] to raise my children normally... without the stress and the hassle of not knowing when he was going to fly off the handle or, or offend physically as well as abusively... keeping the children quiet when he was around, when he was in a mood. (Aaliya) 
His anger, it just happens at a split-second without even a warning. (Lea)

Other women spoke of depression exhibited by men.

My children also were aware that that's his behaviour and he, you know, suffers with depression and mental illness. (Annabelle)

While these references to mood swings and depression provided women with some context for the abuse they suffered, the descriptions also were indicative of the ways in which men used their emotions to control the women and children in the family. At least 13 women spoke of obsessive behaviour, the enforcement of petty rules and stalking behaviours from their partners or ex-partners. Some of these descriptions may be symptomatic of a mental illness while others could be the implementation of strategies intended to abuse and control. Either way, the behaviours had implications for men's fathering.

He insisted on the house always being clean and the girls tidy, lots of rules, etc., so they lived in fear of breaching his expectations. (Lara)

For other women, stalking behaviours were particularly frightening for them and the children. At least 13 women mentioned problems with their partners or ex-partner's ice (methamphetamine), problem drinking or gambling addictions.

\section{Men seeking help}

Most men in this sample did not seek or engage in help seeking activities associated with their violence or parenting. Twenty women (40\%) reported that their partner had attended some form of program either for parenting $(n=7)$ or for men who use violence $(n=8)$. Five men attended both programs. There were three women who were unsure whether their partners had attended any programs.

Four of the five women reporting that their partner attended both types of programs also reported that the programs were not helpful. Belinda believed her ex-partner undertook both a parenting course and an anger management program as a strategy for gaining care of the children.

Having done the course myself, they focus very heavily on trying to get couples to reconcile outside of court, and clearly, that made no difference to him because he did the course and took me to court several months later. (Belinda)

There were five women who believed that the men's use of violence programs were helpful to some extent but still reported problems.

He went to that program. And he was, he was being respectful and helpful and after a little while... I let him move back in. But it didn't last very long... As soon as he was in the house, he stopped going to that ...men's change program. He's just reverted back to the-worse than before. He got more and more controlling. (Mai). 
The women reporting more lasting change were those where men had obtained multiple forms of support, usually a counsellor and psychologist in combination with a violence program.

So that was actually really helpful...He went to the course, he's working on his mental health every day. Like he's committed to being a good dad and being a present father and he supports financially...He's more emotionally present. (Claudia)

In summary, only a minority of men attended parenting programs or men's behaviour change programs that were on offer and women reported very different experiences about their effectiveness.

\section{Discussion}

A concerning picture emerges from the mixed method study. Both the quantitative data from men attending MBC programs for their violence, and the qualitative data from women with experiences of domestic violence show men with high levels of time spent with children, when living with or separated from their partners. While there is no doubt that positive fathering has a highly constructive role to play in the lives of children (Opondo et al, 2016), the evidence suggests that fathers who use domestic violence may create more vulnerability than resilience in the lives of their children (Katz, 2016; Heward-belle, 2016; McGavock \& Spratt, 2017).

The MBC survey indicated $78 \%$ of men were living with children or having extensive, unsupervised contact. The interviews with women showed 31 of 50 men with extensive unsupervised contact with children, 27 (77\%) in cases where women had separated. In this sample, a history of violence was not sufficient reason for contact with children to be curtailed for most men, though several moved to no contact or supervised contact following very serious incidents of abuse. Fathers who use violence were more present than absent in the lives of the children in this study.

The constant reference in the literature to the links between direct (physical and sexual) abuse, domestic violence and the harm to children (Kimball, 2016) are confirmed by the mothers in this study. A group of women grappled with the notion that a man may be 'a bad partner but a good father' (Heward-Belle, 2016). Possibly some of the men may be doing well with their biological children, but not with the children of other men. However, the data suggested many men also found their biological child to be the most difficult child. The majority of women observed that the controlling tactics and abuse used towards them were also being used on children to establish an atmosphere of fear and unpredictability, and that the violence they experienced traumatized their children. This is also a clear finding from a meta-analysis of the research studies (Lourenco et al, 2013). 
The ACEs data (McGavock \& Spratt, 2017) combined with the vulnerability of some young people to repeat the behaviours of their fathers, point to the need for earlier intervention in the lives of children living with domestic violence. Their behaviour highlights the level of distress that they are experiencing. Clear evidence is emerging of the effectiveness of mother-child strengthening interventions in the aftermath of domestic violence (Hegarty et al, 2016; Stover \& Margos, 2013). However, the on-going presence of fathers also indicates the need to develop interventions for all members of the family, including the father of the child (Anonymised). The women's data suggested that a small group of men did well in MBC programs (particularly when other services were also in place), while others had no change or used program attendance to manipulate the system. The evaluation of MBC programs reflects this inconsistency (Kelly \& Westmarland, 2015).

\section{Conclusion}

Together the data point to an urgent need to reconfigure the response to fathers who use violence. A significant number of men who use violence continue to have contact with children. The conflation of separation with safety fails to take account of post-separation contact arrangements for children which often include high levels of unsupervised contact and residency with fathers who use violence. Additionally, many families do not separate, or men move in with new families.

Naming men who use violence towards their partners as 'fathers who use violence' identifies the relationship between domestic violence and the harm to children (anonymised). It also recognises that a significant group of men who use violence towards their partners are also involved in direct forms of child abuse. Yet the intervention system is not set up to respond to fathers who use violence. Few MBC programs in Australia have fathering as their primary remit and new programs are only latterly emerging and are not consistently funded (McConnell et al, 2016; Scott \& Crooks, 2007). While there is some evidence that men are motivated by wanting to be a good father (Stanley, Graham-Kevan, \& Borthwick, 2012), the reports from women suggest that many of them are disinterested in their fathering until separation is threatened or occurs. They may be ill prepared for their post-separation fathering roles.

Mainstream parenting programs are also not designed to work with fathers who use violence. They do not deal with issues of trauma and the need for reparation and are often developed to help parents (mothers) provide appropriate boundaries and discipline for their children. Highly controlling fathers do not necessarily perceive themselves as having problems in these areas of their parenting (Fox \& Benson, 2004).

Finally, the private and family law system requires further attention. Not all fathers have a 'right' to be involved in their children's lives when their parenting practices are, or have 
been abusive. Many children were in unsupervised contact arrangements with abusive fathers. This has been a contentious issue for decades (Radford \& Hester, 2006), but one in which the long-term impacts of the abuse and the short term consequences of trauma require continued advocacy for change.

Fathers who use violence are more present than absent in the lives of their children. An intervention system that recognises and responds to the needs of children and the accountability of fathers to their children has been slow to develop. It is an area which is ripe for change and where new language, new programs and new responses are required that privilege the rights of children to live free from violence and fear.

\section{References}

Anonymous(2017)

Anonymous (2016)

Creswell, J. \& Plano Clark, V. (2007) Designing and conducting mixed methods research. Thousand Oaks, CA: Sage Publications.

Fox, G., \& Benson, M. (2004) Violent men, bad dads? Fathering profiles of men involved in intimate partner violence. (eds) R. Day \& M. Lamb (Eds.), Conceptualizing and measuring father involvement. New Jersey, Lawrence Erlbaum Publishers.

Hartley, C. (2004) Severe domestic violence and child maltreatment: considering child physical abuse, neglect and failure to protect. Children and Youth Services Review, 26, 373392.

Hegarty, K., Tarzia,L., Hooker, L. \& Taft, A. (2016) Interventions to support recovery after domestic and sexual violence in primary care, International Review of Psychiatry, 28:5, 519532

Hester, M. (2011) The three planet model: Towards an understanding of contradiction in approaches to women and children's safety in the context of domestic violence. British Journal of Social Work, 41(837-853).

Heward-Belle, S. (2016) The Diverse Fathering Practices of Men Who Perpetrate Domestic Violence. Australian Social Work. 32, 374-389.

Holt, S., Buckley, H. and Whelan, S. (2008) The impact of exposure to domestic violence on children and young people: a review of the literature. Child Abuse and Neglect, 32, 797-810.

Johnson, R., Onwuegbuzie, A., \& Turner, L. (2007) Toward a definition of mixed methods research. Journal of Mixed Methods Research, 1, 112-133. 
Katz, E. (2016) Beyond the physical incident Model: How children living with domestic violence are harmed by and resist regimes of coercive control. Child Abuse Review, 25, 4659

Kelly, L. (1994) The Interconnectedness of Domestic Violence and Child Abuse: Challenges for Research, Policy and Practice', in A. Mullender, A. and R. Morley, (eds) Children Living With Domestic Violence, London: Whiting and Birch.

Kelly, L., \& Westmarland, N. (2015) Domestic Violence Perpetrator Programmes: Steps Towards Change. London and Durham: London Metropolitan University and Durham University. https://www.dur.ac.uk/criva/projectmirabal

Kimball, E. (2016) Edleson Revisited: Reviewing Children's Witnessing of Domestic Violence 15 Years Later. Journal of Family Violence, 31, 625-637.

Levendosky A., Bogat, G., Martinez-Torteya C. (2013) PTSD symptoms in young children exposed to intimate partner violence. Violence Against Women, 19, 187-201.

Lourenço, L. M., Baptista, M. N., Senra, L. X., Almeida, A. A., Basílio, C., \& Bhona, F. M. C. (2013) Consequences of exposure to domestic violence for children: a systematic review of the literature. Paideia, 23, 263-271.

Mandel, D. (2014) Beyond domestic violence perpetrator accountability in child welfare systems. The No to Violence Journal, Spring, 50-85.

McConnell, N., Barnard, M., Holdsworth, T. and Taylor, J. (2016) Caring Dads: Safer Children Evaluation Report. Evidence and Practice Series. London: NSPCC.

McGavock, L. \& Spratt, T. (2017) Children exposed to domestic violence: Using adverse childhood experience scores to inform service response. British Journal of Social Work, 47, 1128-1146.

McTavish, J. R., MacGregor, J. C. D., Wathen, N., \& MacMillan, L. (2016) Children's exposure to intimate partner violence: an overview. International Review of Psychiatry, 28, 504-518.

Opondo, C., Redshaw, M., Savage-McGlynn, E. \& Quigley, M. (2016) Father involvement in early child-rearing and behavioural outcomes in their pre-adolescent children: evidence from the ALSPAC UK birth cohort. BMJ Open, 6, e012034.

Oral, R., Ramirez, M., Coohey, C., Nakada, S.,Walz, A., Kuntz, A., Benoit, J. \& Peek-Asa, C. (2016) Adverse childhood experiences and trauma informed care: the future of health care. Pediatric Research, 79, 227-233.

Radford, L. and Hester, M. (2006) Mothering Through Domestic Violence. London: Jessica Kingsley. 
Rezey, M. (early access 2017) Separated Women's Risk for Intimate Partner Violence: A Multiyear Analysis Using the National Crime Victimization Survey. Journal of Interpersonal Violence. doi/10.1177/0886260517692334

Ross, S. (1996) Risk of physical abuse to children of spouse abusing parents. Child Abuse and Neglect, 20, 589-598.

Scott, K., and Crooks, C. (2007). Preliminary evaluation of an intervention program for maltreating fathers. Brief Treatment and Crisis Intervention, 7, 224-238.

Stanley, N,6Graham-Kevan, N, and Borthwick, R. (2012). Fathers and Domestic Violence building motivation for change through perpetrator programmes. Child Abuse Review, 21, 264-274.

Stover, C., \& Margos, D. (2013) Fatherhood and intimate partner violence: Bringing the parenting role into intervention strategies. Professional Psychology: Research and Practice, 44,247

Thomas, J. \& Harden, A. (2008) Methods for the thematic synthesis of qualitative research in systematic reviews. BMC Medical Research Methodology, 8, 45. doi:10.1186/1471-2288-845.

Thompson-Walsh, C., Scott, K., Dyson, A. \& Lishank, V. (2018) Are we in this together? Postseparation co-parenting of fathers with and without a history of domestic violence. Child Abuse Review. DOI: 10.1002/car

Walby, S. and Allen, J. (2004) Domestic violence, sexual assault and stalking: findings from the British Crime Survey. Home Office Research Study 276. London, Home Office. 
Table 1: Frequency of contact

\section{Percent}

All the time as we are part of

the same household

More than once a week

Once a week

Every second week

Monthly

Occasionally (no regular contact)

Once or twice a year

Not at all

Not answered

$1 \%$

$100 \%$

\section{Count}

9

1

4

2


Table 2: Relationship Status

\begin{tabular}{|c|c|c|}
\hline Relationship Status & Percent & Count \\
\hline Single & $9 \%$ & 9 \\
\hline Separated/divorced & $28 \%$ & 28 \\
\hline Married or de facto - living with partner & $47 \%$ & 47 \\
\hline In a relationship - not living together & $16 \%$ & 16 \\
\hline Widowed & $1 \%$ & 1 \\
\hline Total & $100 \%$ & 101 \\
\hline
\end{tabular}

This article is protected by copyright. All rights reserved. 
Table 3: Gender and relationship to the most difficult child to parent

\begin{tabular}{|c|c|c|}
\hline $\begin{array}{l}\text { Gender of child you find most difficult } \\
\text { to parent }\end{array}$ & Percent & Count \\
\hline Male & $62 \%$ & 62 \\
\hline Female & $38 \%$ & 38 \\
\hline $\begin{array}{l}\text { Total } \\
\text { Is the child you find most difficult to } \\
\text { parent a biological child of yours? }\end{array}$ & $100 \%$ & 100 \\
\hline Yes & $77 \%$ & 78 \\
\hline No & $23 \%$ & 23 \\
\hline Total & $100 \%$ & 101 \\
\hline
\end{tabular}

*Total does not equal 101 due missing responses 
Table 4: Frequencycy of forms of child abuse

\begin{tabular}{|l|c|}
\hline Forms of child abuse & Total ( $\mathbf{~ = 4 5 )}$ \\
\hline Psychological/emotional abuse & 31 \\
\hline $\begin{array}{l}\text { Child witnessed violence against mother or other family } \\
\text { member }\end{array}$ & 31 \\
\hline Child was a direct victim of family violence with mother & 13 \\
\hline Physical abuse & 5 \\
\hline Sexual abuse of child & 5 \\
\hline Neglect of child & $\mathbf{1 0 2}$ \\
\hline Total forms of child abuse & 17 \\
\hline
\end{tabular}




\section{University Library}

\section{- M M N E R VA A gateway to Melbourne's research publications}

Minerva Access is the Institutional Repository of The University of Melbourne

Author/s:

Humphreys, C;Diemer, K;Bornemisza, A;Spiteri-Staines, A;Kaspiew, R;Horsfall, B

Title:

More present than absent: Men who use domestic violence and their fathering

Date:

2019-05-01

Citation:

Humphreys, C., Diemer, K., Bornemisza, A., Spiteri-Staines, A., Kaspiew, R. \& Horsfall, B. (2019). More present than absent: Men who use domestic violence and their fathering. CHILD \& FAMILY SOCIAL WORK, 24 (2), pp.321-329. https://doi.org/10.1111/cfs.12617.

Persistent Link:

http://hdl.handle.net/11343/284799 